\title{
Referencing patterns in South African Journal of Libraries and Information Science, 1996 - 2007
}

\author{
Omwoyo Bosire Onyanchal \\ b_onyancha@yahoo.com or onyanob@unisa.ac.za
}

Jan R. Maluleka ${ }^{2}$

maluljr@unisa.ac.za

University of South Africa, Department of Information Science, P.O Box 392, UNISA 0003, Pretoria, South Africa

\begin{abstract}
This study uses bibliometric techniques to examine the frequency and patterns of referencing in articles published in South African Journal of Libraries and Information Science (SAJLIS) from 1996 to 2007. The authors believe that an analysis of references and referencing patterns in a journal is vital because references play an important role in scholarly communication, which is defined as the process of sharing and publishing research findings in order to reach a wider scholarly and professional community. This paper thus seeks to determine, among other objectives: the growth of publications in the journal; the growth of references; articles with the most number of references; types of sources consulted by SAJLIS authors; language used to publish the consulted sources; and whether the length of articles influences the number of references. It was found that SAJLIS has maintained regular publication for all but one year, 1999, when the journal was not published. On average, SAJLIS published 15 articles per year between 1996 and 2007; journal articles were the most commonly consulted document type by SAJLIS authors $(2241 ; 46.6 \%)$, followed by books (I5I $2 ; 31.5 \%)$, Internet-based sources (665; 13.8\%), and conference proceedings (189; 3.9\%); Internet-based sources and electronic journals were growing in popularity among the researchers; the average number of references per article equated to 29. 13; and the highest and lowest number of references recorded in a single article were 101 and 4, respectively. We also observed that the number of references in an article does not influence the length of the article; the average length of SAJLIS papers is 10 pages and there was an increased usage of electronic resources by SAJLIS authors from 200I. Finally, this paper draws several conclusions based on the findings of the study and provides some recommendations for further research.
\end{abstract}

Key words: References; South African Journal of Libraries and Information Science; informetrics; information science; citations; journals; South Africa

\section{Introduction}

The South African Journal of Libraries and Information Science [ISSN: 0256-886I] (SAJLIS) celebrates 74 years of its existence this year (2008). The journal began its publication in 1933. Its former titles before 1983 include "South African Journal of Librarianship and Information Science" [ISSN: 0256-887X] and "South African Libraries - Suid-Afrikaanse Biblioteke (South Africa)" [ISSN: 0038-240X]. SAJLIS was known as the "South African Journal of Library and Information Science" until 2002, when it changed to its current name. The journal was supposed to be published quarterly, largely in the English language. Manuscripts in the Afrikaans language (which is ranked as the 3rd most common language of communication in South Africa) [Onyancha, 2006:6I] were also accepted for publication in SAJLIS. Presently, SAJLIS is owned by the Library and Information Science Association of South Africa (LIASA), which took over ownership and management from the defunct South African Institute of Library and Information Science (SAILIS). It is published in South Africa by Forum Press, which replaced the South African Bureau for Scientific Publications. The journal publishes original, scientifically viable contributions on any area of Library and Information Science (LIS), including library science, information science, archives and records management and Information and Communication Technologies (ICTs). Specific areas of publication focus on literacy, management, children's literature, ethics, globalisation, impact of the digital divide, technology, communications, Indigenous Knowledge Systems (IKS), knowledge management, etc. According to the journal's editorial policy (available on LIASA's website), SAJLIS publishes a range of documents, including scholarly articles, review articles, practical library work, short communications, book reviews and letters to the editor. More information about the journal can be found at: http://www.liasa.org.za/publications/sajlis.php.

Information provided in the Ulrich's Periodical Directory (C)2008 reveals that the journal's articles are available electronically in the following databases: Die Elektronische Zeitschriftenbibliothek (Zeitschriften (alle); Zeitschriften (kostenpflichtig) and EBSCOhost (Academic Search Complete; Academic Search Elite; Academic Search Premier; Academic Source Premier; Advanced Placement Source; Business Source Corporate; EBSCOhost MegaFILE; Education

I. Omwoyo Bosire Onyancha, Ph.D., is a post-doctoral researcher and temporary senior lecturer in the Department of Information Science, University of South Africa and deputy librarian, University of Eastern Africa, Baraton, Kenya.

2. Jan Maluleka is a post-graduate honours student in the Department of Information Science, University of South Africa 
Research Complete; Library, Information Science and Technology Abstracts with Full Text; MasterFILE Premier; Professional Development Collection; and World Magazine Bank). It is indexed in 25 world renowned electronic databases, including EBSCOHost's 15 bibliographic databases and H.W. Wilson's Library Literature \& Information Science Full text database. Other indexing services that index SAJLIS include: Index to South African Periodicals (ISAP-online); Information Science \& Technology Abstracts (Online) (1986-); Inspec (Dec. 1985-); Internationale Bibliographie der Rezensionen Geistes- und Sozialwissenschaftlicher Literatur; LISA: Library \& Information Science Abstracts (2004-); Library Literature \& Information Science (Mar. 1984-); Library, Information Science \& Technology Abstracts (Jan. 1995-); World Banking Abstracts (Jan. 1995-) and World Magazine Bank.

Its current Editorial Board features 26 established and experienced scholars in the field of library and information science/studies (LIS), mostly from South Africa, with others from Australia, Botswana, Canada, Denmark, Ghana, Hungary, Kenya, Namibia, Nigeria, the United Kingdom and the United States of America. According to Ocholla (2005), the journal draws its funding from subscriptions, government subsidies, advertising and donations (e.g. Lotto Development Trust Fund), and page fees. Based on these developments (especially changes in the leadership of the journal's management team) as well as the $74^{\text {th }}$ anniversary of SAJLIS, we conduct this study in order to examine the performance of the journal since 1996, two years after South Africa was accepted into the international scholarly arena, among other incentives. We believe that a review of SAJLIS will inform researchers/authors, the journal management and the owners and other stakeholders about the current status and future prospects of the journal as far as publication trends are concerned. Informed decisions can then be made regarding the improvement of the quality of the journal. This study specifically deals with one of many aspects that influence the quality of scholarly publishing or communication, i.e. references and referencing patterns in SAJLIS.

\section{The concepts 'references' and 'citations'}

The terms 'reference' and 'citation' are commonly used interchangeably. There is, however, a difference between the two terms. Smith (1981:83) defines a citation as an "acknowledgement that one document receives from another", while a reference is the "acknowledgement that one document gives to another". The difference therefore lies in the words 'receives' and 'gives', which introduce other terms such as cited and citing documents. Diodato (1994:136) explains that a reference is a "publication mentioned in a document, usually in the document's footnotes, endnotes, bibliography or list of references" and describes a citation thus: "When document $A$ is mentioned in document $B$, the mention is a citation for document A". Simply put, one document's reference is another's citation. In order to clearly appreciate the difference between the two terms, Diodato's (1984:32) explanation is graphically illustrated in Fig I.
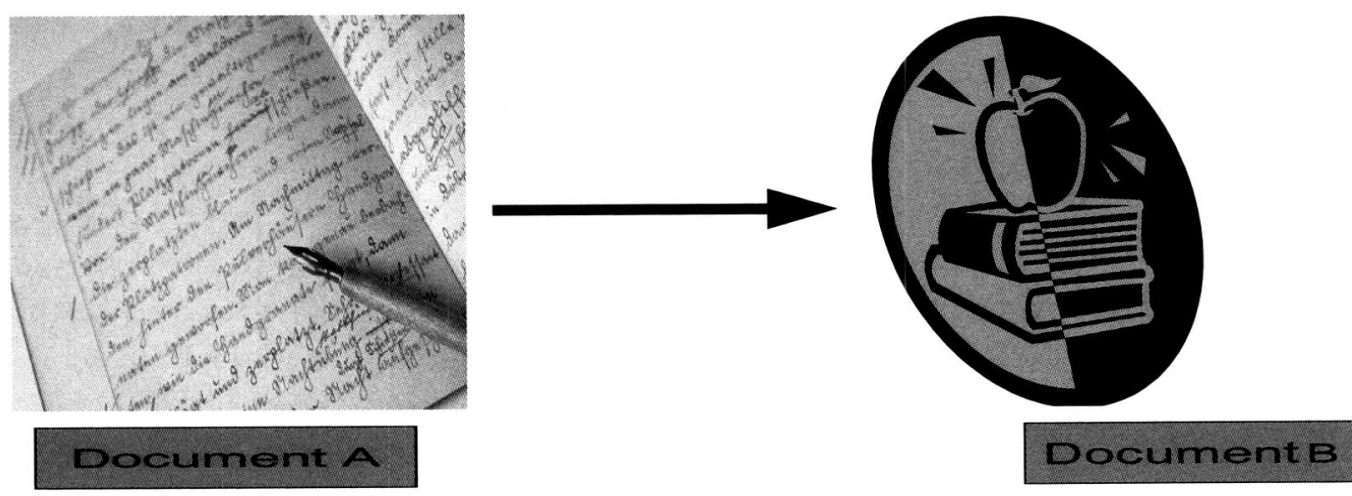

Fig 1: Relationship between a reference and citation

Assume that document B appears in the footnotes (bibliography or list of references) of document A. It follows therefore that:

Document $A$ gives document $B$ as a reference;

Document $A$ refers to document $B$;

Document $A$ cites document $B$;

and that:

Document $B$ receives a citation from document $A$;

Document $B$ receives a reference from Document $A$; and

Document $B$ is cited by document $A$. 
Using the citation count and analysis approach, document B can be said to have received one citation from document $A$. In other words, document $B$ will be credited with one citation, while document $A$ will be said to be containing a reference to document $B$. Document $A$, in this case, is not credited with any citation count or frequency. In this study, it is this latter category of acknowledgement that will be the subject of analysis. That is, we focus on the publications mentioned in SAJLIS as opposed to the analysis of the publications that mention SAJLIS in their footnotes, bibliography, endnotes or list of references. Only references in SAJLIS as opposed to references to SAJLIS will be analysed in this study.

According to Neville (2007:I), referencing is the practice of acknowledging, in one's own text or writing the intellectual work of others - specifically work that has been presented in some way in the public domain. It is a way that uniquely identifies the sources of information. Ojedokun (2007) explains that referencing is necessary to: avoid plagiarism; help support a scholar's arguments and add credibility to their writings; trace the origin of ideas; and spread knowledge. By looking at the list of sources cited, Neville (2007:8) posits that the reader can follow up and explore the text more comprehensively, or extract further sources for their own writing. Thomas \& Goldman (2007:3) suggest that references should be used when one: quotes the exact words of another author; presents someone else's ideas, theories, arguments and/or research in one's own words; presents another author's interpretation, point of view, opinion or understanding of an issue; and provides specific, factual information in the form of statistics, graphs, verbal interviews, diaries etc.

In bibliometrics, references play an important role in research evaluation and/or citation analysis. In scholarly communication and sociology, references can be used to study how and why scholars communicate with each other by analysing who cites who and why (the latter is used to explain the motivations behind one scholar's use of another's work). Citations can also be used to measure an author's, journal's or institution's research influence. However, the use of citations as a measure of influence is based on a number of assumptions and has several limitations, some of which are as follows (Ungern-Sternberg, 2000):

- Citing a document is supposed to mean that the author has been used by another author.

- Citing a document reflects quality.

- The best works are cited. Often factors other than quality determine what is cited, e.g. availability, coverage by bibliographic databases, format, age, language etc.

- The content of a citing document is related to the content of the cited document.

- All citations are equal.

- Formal influence is not always cited.

- Biased and incorrect citations are common.

- Informal influence is not cited.

- The types of citations vary.

- Variations in the degree of citation are dependent on the type of publication, nationality, time period, size and type of speciality. The citing behaviour varies in different subject fields, but the general trend is towards more citations.

\section{Related studies}

Similar studies have been undertaken in different subject fields and disciplines (including LIS), where bibliometric research techniques were applied in an attempt to identify bibliometric characteristics of articles in scholarly journals. Specifically, the study of references and referencing patterns in journal articles has also received a considerable amount of interest from LIS researchers. The scope of some of the studies is broad, but they nevertheless analyse references. For instance, Tiew, Abdullah and Kaur (2002) conducted a bibliometric study on the Malaysian Journal of Library and Information Science (MJLIS) in which about 76 journal articles published in MJLIS from $1996-2000$ were examined. Among the factors that the authors examined were: the range of articles published per volume, the average number of references, average length per article and the authorship patterns. Glanzel \& Schoepflin (1999) conducted a study that analysed the percentage of references to serials, the mean references' age and the mean reference rate in their paper entitled "A bibliometric study of reference literature in the sciences and social sciences". In his paper, "The influence of references per paper in the SCl to impact factors and the Matthew effect", Biglu (2008) studied the references in 10,000 records randomly selected from the Science Citation Index, and observed that the number of references per paper has continued to increase, while most cited references were in the form of journal articles, followed by meetings' abstracts, notes and editorial material. He also noted that most references were in the English language, implying that the majority of the publications consulted were published in English. Other languages included German, Russian and French. A similar study was carried out by Krampen, Becker, Wahner \& Montada (2007), who conducted a content analysis on the references and citations in psychological publications and found that more than $50 \%$ of the examined references were journal articles, and up to $40 \%$ were books and book chapters. Internet references (or references to internet-based sources) have also been subjected to research. Aronsky, Madani, Carnevale, Duda \& Feyder (2007) examined 840 internet sources in order to determine the prevalence and inaccessibility of internet references in the bibliography of biomedical 
publications. The authors discovered that $11.9 \%$ of the references were already inaccessible within two days of the articles release to the public, and concluded that the inaccessibility rate at the time of publication was substantial. On their part, Vallmitjana \& Sabate (2008) conducted a bibliometric study to ascertain the types of documents most frequently used in the research process, the most frequently consulted journals, and the obsolescence rate of the journals, and noted that of the 4203 citations analysed, scientific papers accounted for $79 \%$; 33 journals met $50 \%$ of the information needs; and $50 \%$ of the citations were no older than 9 years.

In Sub-Saharan Africa, Mabawonku (200I) conducted a study in which papers published in the African Journal of Library, Archives and Information Science (AJLAIS) during the 1996-2000 period were analysed. The study focused on the country in which the papers were submitted; where the authors received their professional training; major disciplines covered in the profession; format of the cited publication; time-span of citations; and the ranking of cited journals. The intention was to map the changing pattern of LIS research in Africa. Similarly, Ocholla \& Ocholla (2007) conducted a study that aimed to promote awareness of the overall research output about Library and Information Science in South Africa. The publication count and analysis approaches were used to determine the nature, type and range of research output in LIS in South Africa. Omotayo (2004) and Kirchler (2006) also conducted bibliometric studies that analysed the Ife psychologia and the Journal of Economic Psychology respectively. Foster in Ocholla (2007:5) notes that a manuscript is rated as good when its references are current and concise. In his study on the "Common errors and challenges in publishing in a peer refereed library and information journal", Ocholla (2007) expounds further on the role of references in scholarly communication. Among the referencing errors that are committed by authors, he cites: inappropriate referencing styles, lack of South African references, weak bibliography and poor electronic referencing (Ocholla, 2007:10). The author observed thus:

... we also noted that referencing $(33 ; 38.8 \%)$, conclusions and recommendations $(33 ; 38.8 \%)$, among others $\ldots$ are errors that require attention. For instance, although journals provide guidelines on referencing style, authors grapple with referencing, particularly with electronic referencing. Also common, although not easily detected, are mismatched references between the body of the manuscript and those presented in the reference list/bibliography at the back (Ocholla, 2007:10).

As illustrated by the aforementioned studies, South African LIS journals have received very little attention from LIS researchers. It is worth noting that most of the studies under review in this study are based in the developed countries and their findings may therefore not reflect the status of journals published in South Africa or Sub-Saharan Africa. Given that journal publishing in the developing countries and more particularly in Africa faces more severe challenges than those published in the industrialised nations, it is imperative that we continuously evaluate them to ascertain their scholarliness and quality. One of the factors that influence the quality of articles (and by extension, the journal) is references. As Foster in Ocholla (2007:5) notes, a manuscript is rated as good when its references are current and concise. This study, unlike some of the studies reviewed above which analysed a broad spectrum of variables, will concentrate on the analysis of references in SAJLIS. SAJLIS is South Africa's leading LIS journal in terms of LIS research productivity and impact. It is the mouth piece of LIS in the country. Other active LIS journals in South Africa include Mousaion, Innovation, Indilinga, South African Journal of Information Management, and Journal of the Eastern and Southern Africa Regional Branch of the International Council on Archives (ESARBICA journal).

\section{Purpose of the study}

This study builds on some of the aforementioned studies and examines the references and referencing patterns in articles published in South African Journal of Libraries and Information Science (SAJLIS) between 1996 and 2007 in order to determine the:

- Growth of publications;

- Distribution of records by document type;

- Number of references per year;

- Average number of references per article per year;

- Articles with the most number of references;

- Language of publication of the cited sources;

- Relationship between the length of articles and the number of references; and

- Types of sources most consulted by SAJLIS authors

\section{Methodology}

This study applied bibliometric research techniques to analyse articles published in SAJLIS between 1996 and 2007. Bibliometric research methods can be divided into two broad categories, namely descriptive (i.e. publications count and analysis) and evaluative (citations count and analysis) research methods. Both approaches were used in this study. Whereas publications count was used to obtain the number of articles (and other documents) published in SAJLIS within 
the period of review, evaluative techniques were employed to study the referencing patterns in the journal. Three electronic sources of data, namely Academic Search Premier; Master File Premier; and Library, Information Science \& Technology Abstracts (LISTA); were used to collect relevant data. The journal's name was used to search for SAJLIS' published records as indexed in the above databases. The full-text documents were then identified, downloaded and stored for analysis. In cases of uncertainty about the total number of articles in each issue, or where some issues were missing from the electronic databases, the UNISA library journal collection was consulted. The missing issues or articles were then photocopied and their references obtained for further analysis. Extra care was taken to ensure that most (if not all) articles were obtained by additionally searching Google Scholar using Harzing's Publish or Perish Software. The data obtained from Google Scholar was used to confirm the number of articles published in SAJLIS between 1996 and 2007. It was noted that in some years, Google Scholar yielded more documents but fewer articles than the bibliographic databases mentioned above. This information was used to conduct further searches in the UNISA library for the missing articles.

The references were manually counted and electronically fed into spreadsheets that were prepared using Microsoft Excel software. Data was then analysed to determine:

- The growth of publications in SAJLIS by obtaining the number of records published in each year, from 1996 to 2007

- The type of documents published in SAJLIS based on information that was available in the 'document type' field

- The number of references per year, by first counting the number of references in each article in a given year, and then summing up the figures for each year

- The average number of references per article per year, which was calculated as the total number of references divided by the total number of articles in a given year

- The articles with the most number of references, accomplished by identifying the articles that contained the highest number of references in their list of references

- The language of publication of cited sources, by examining the language in which the title of the cited sources was written

- The relationship between the length of the article and number of references, which was measured using the Pearson correlation formula as explained further below. The length of the articles was measured in terms of the total number of pages of each article

- The types of sources consulted by SAJLIS authors, which were obtained by examining the titles of the sources of the consulted documents. For instance, if the sources' titles were italicised and/or contained the volume and issue number and pagination (e.g. The International Information \& Library Review, 36:95-103), the reference was categorised as a journal article. If, it additionally contained a Uniform Resource Locator (URL) or website address, the reference was categorised as an electronic journal article

In addition to the mean, other descriptive statistics (e.g. mode, median and standard deviation) were generated using Microsoft Excel's descriptive statistics option by selecting Tools > > Data analysis > > Descriptive statistics, as shown in Fig 2. The generated statistics are provided in Table 8.

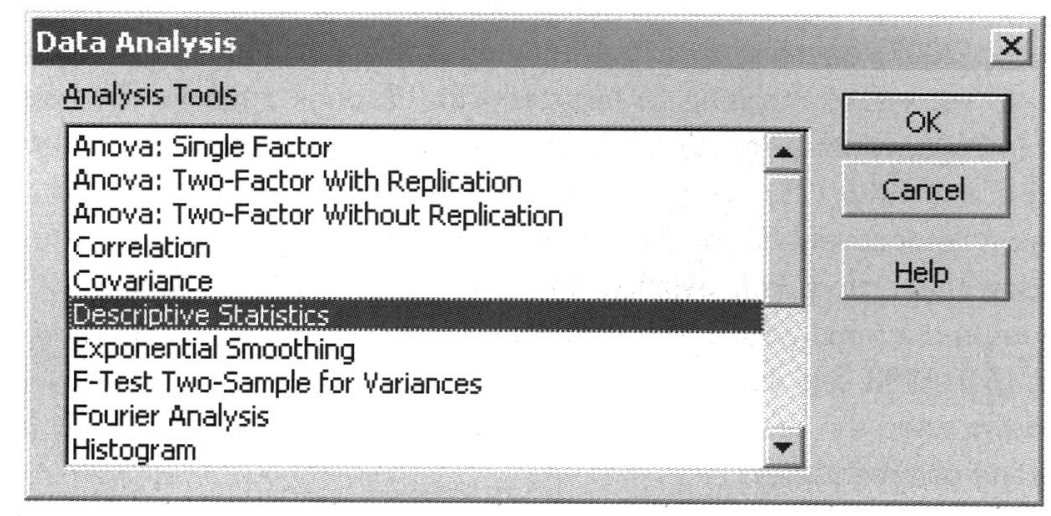

Fig 2: Microsoft Excel's data analysis option for various statistical analyses

The following Pearson's correlation formula was used to calculate the correlation between the number of references and the length of articles in each year.

$$
r=\frac{\sum(x-\bar{x})(y-\bar{y})}{\sqrt{\sum(x-\bar{x})^{2} \sum(y-\bar{y})^{2}}}
$$


This formula is one of the most commonly used methods to determine the relationship between a set of variables. The formula returns the Pearson product moment correlation coefficient $[r]$, a dimensionless index that ranges from -1.0 to I.0 (inclusive), and reflects the extent of a linear relationship between two data sets.

\section{Results}

In this section, the results of the study are presented under the following subheadings: growth of publications in SAJLIS; distribution of records by document type; number of references per year; average number of references per article per year; articles with the most number of references; relationship between the length of articles and the number of references; average number of pages per article; language of cited sources; and types of sources mostly often consulted.

\section{I Growth of Publications in SAJLIS}

In total, 165 articles were published by SAJLIS between 1996 and 2007, as shown in Table I. Evidently, the publication of SAJLIS has been regular over the years except for 1999, when no issue was published. Most articles were published in 2005 (25), followed by 1997 (23), 2006 (22), 1996 (I8), 2007 (I7), 1998 (I6), 2004 (12), 2002 (10) and 2003 (10). The least number of publications was recorded in 2000 (5), followed by 2001 with 7. On average, and with the exception of 1999, SAJLIS published I5 articles per year. Table I also reveals that between 1999 and 2003, the journal published relatively fewer records than the period preceding 1999 and following 2003.

Table I Growth of Articles in SAJLIS

\begin{tabular}{cccccc}
\hline Year & Articles & change in \% & cumulative & $\begin{array}{c}\text { Change in } \\
\text { cumulative }\end{array}$ & $\begin{array}{c}\text { \% incumulative } \\
\text { change }\end{array}$ \\
\hline 2007 & 17 & -22.72 & 165 & 17 & 11.48 \\
2006 & 22 & -12 & 148 & 22 & 17.46 \\
2005 & 25 & 108.33 & 126 & 25 & 24.75 \\
2004 & 12 & 20 & 101 & 12 & 13.48 \\
2003 & 10 & 0 & 89 & 10 & 12.65 \\
2002 & 10 & 42.85 & 79 & 10 & 14.49 \\
2001 & 7 & 40 & 69 & 7 & 11.29 \\
2000 & 5 & - & 62 & 5 & 8.77 \\
1999 & 0 & -100 & 57 & 0 & 0 \\
1998 & 16 & -30.43 & 57 & 16 & 39.02 \\
1997 & 23 & 27.77 & 41 & 23 & 127.77 \\
1996 & 18 & & 18 & & \\
\hline
\end{tabular}

\subsection{Distribution of records by document type}

Table 2 reveals that a total of 165 articles, 85 book reviews, 10 editorials, 2 commentaries and 3 reports were published in SAJLIS between 1996 and 2007, equating to a total of 265 documents. The highest number of documents was published in 1997, with 42 records comprising 23 articles and 19 book reviews. The second highest number of documents was published in 2006, when 22 articles, 16 book reviews and 3 editorials were recorded; followed by 2005 (39), 1998 (3I), 2007 (28), and 1996 (25). The least number of records were published in 2000 and 200I, which recorded 5 and 7 publication respectively. Throughout the entire period of review [i.e.1996-2007], the journal articles constituted the majority document type. For instance, there were 18 journal articles in 1996 as opposed to 5 book reviews and 2 commentaries in the same year. The distribution pattern of documents in Table 2 reveals that there were 23 journal articles in 1997, 16 in 1998, 5 in 2000, 7 in 200 I, 10 each in 2002 and 2003, 12 in 2004, 25 in 2005, 22 in 2006 and 17 in 2007 . Book reviews were the second most published document type with a total posting of 85 , followed by editorials ( 10$)$, reports (3) and commentaries ( 1 ). 
Table 2 Distribution of records by document type

\begin{tabular}{ccccccc}
\hline Year & Articles & Book reviews & Editorials & Commentary & Reports & Total \\
\hline 1996 & 18 & 5 & & 2 & 25 \\
1997 & 23 & 19 & & & 42 \\
1998 & 16 & 15 & - & - & - & - \\
1999 & - & - & & & 5 \\
2000 & 5 & & & & 7 \\
2001 & 7 & 2 & 1 & & 16 \\
2002 & 10 & 5 & & & 16 \\
2003 & 10 & 3 & 2 & & 15 \\
2004 & 12 & 12 & 3 & & 39 \\
2005 & 25 & 16 & 2 & & 4 \\
2006 & 22 & 8 & 10 & 2 & 3 \\
2007 & 17 & 85 & & & 28 \\
Total & 165 & & & & & 2 \\
\hline
\end{tabular}

Table 3 Number of references per year

\begin{tabular}{ccccc}
\hline References & \%Change & Cumulative references & $\begin{array}{c}\text { \% Change in cumulative } \\
\text { references }\end{array}$ \\
\hline 2007 & 514 & -36.54 & 4807 & 11.97 \\
2006 & 810 & 3.32 & 4293 & 23.26 \\
2005 & 784 & 104.17 & 3483 & 29.05 \\
2004 & 384 & 14.29 & 2699 & 16.59 \\
2003 & 336 & 43.59 & 2315 & 16.98 \\
2002 & 234 & 27.87 & 1979 & 13.41 \\
2001 & 183 & 77.67 & 1745 & 11.72 \\
2000 & 103 & -72.53 & 1562 & 7.06 \\
1998 & 375 & -40.10 & 1459 & 34.59 \\
1997 & 626 & 36.68 & 1084 & 136.68 \\
1996 & 458 & - & 458 & - \\
\hline
\end{tabular}

\subsection{Number of references per year}

The total number of references discerned from a total of 165 articles published in SAJLIS between 1996 and 2007 was 4807, as indicated in Table 3. The year 2006 produced the highest number of references (i.e. 810), which implies that a total of 810 sources were consulted by SAJLIS authors in that year alone. The second highest number of references was recorded in 2005, which yielded a total of 784 references, followed by 1997 (626), 2007 (514), 1996 (458), 2004 (384), 1998 (375), and 2003 (336).

The least number of references were recorded in the years 2000 (103) and 2001 (183). There was a negative growth in the percentage of references in the years $1998(-40.10 \%), 2000(-72.53 \%)$ and $2007(-36.54 \%)$, implying a decline in the number of sources consulted by SAJLIS authors. Other than the above mentioned years, a positive growth rate was generally witnessed, with the highest percentage growth rate recorded in 2005 (104.17\%), followed by 200 I (77.67\%), and 1997 (36.68). Generally speaking, the percentage change in the cumulative number of references shows a positive growth rate, from 458 references in 1996 to the accumulative total of 4807 references by 2007.

\subsection{Average number of references per article per year}

One of the most commonly used measures of central tendency is the mean (known as the arithmetic mean or simply, the average). Other measures of central tendency include the mode, median and standard deviation (see Table 8). Overall, the average number of references per article for all the articles published in SAJLIS between 1996 and 2007 was 29.3 (see Table 4). Table 4 further reveals that the average number of references per article ranged between 20.6 (recorded in 2004) and 36.8I (in 1997). Thus, the years that produced the highest average number of sources consulted between 
1996 and 2007 by SAJLIS authors were as follows: 1997 (36.8I), 200 I (33.60), 1996 (30.23), 2006 (27.2I), 2003 (26. I4), and 2007 (25.44).

Table 4 Average number of references per article per year

\begin{tabular}{cccc}
\hline Year & References & Articles & References/Article \\
\hline 2007 & 458 & 18 & 25.44 \\
2006 & 626 & 23 & 27.21 \\
2005 & 375 & 16 & 23.43 \\
2004 & 103 & 5 & 20.60 \\
2003 & 183 & 7 & 26.14 \\
2002 & 234 & 10 & 23.40 \\
2001 & 336 & 10 & 33.60 \\
2000 & 384 & 12 & 32.00 \\
1998 & 784 & 25 & 31.36 \\
1997 & 810 & 22 & 36.81 \\
1996 & 514 & 17 & 30.23 \\
Total & 4807 & 165 & 29.13 \\
\hline
\end{tabular}

\subsection{Articles with the most references}

Appendix A shows the top 20 articles that recorded the highest number of references. The articles that yielded 60 or more references each, in descending order, were: Fourie I (I0I); Ikoja-Odongo R \& Mostert (87); Stilwell C \& Morris C (82); Ngulube P \& Magazi L (73) and Migiro, S O (73). Others were Fourie J A (7I), Dick A L (62), Dube L \& Ocholla D N $(61)$, and Murray $\mathrm{K}(60)$. Therefore, the article with the most number of references contained $10 \mathrm{I}$ references, while the article ranked $20^{\text {th }}$ had 45 references. Of the 20 highest ranked articles, 6 had over 70 references. The bottom 5 articles, i.e. with the least number of references, had II, 9, 7, 6 and 4 references respectively.

Table 5 Length of articles in relation to the number of references

\begin{tabular}{cccc}
\hline & Total no. of Pages & $\begin{array}{c}\text { Total no. of } \\
\text { References }\end{array}$ & $\begin{array}{c}\text { Pearson's correlation } \\
\text { Coefficient }(\boldsymbol{r})\end{array}$ \\
\hline 2007 & 145 & 458 & 0.364686 \\
2006 & 196 & 625 & 0.526694 \\
2005 & 131 & 375 & 0.628247 \\
2004 & 49 & 103 & 0.823239 \\
2003 & 64 & 183 & 0.366234 \\
2002 & 109 & 234 & 0.451834 \\
2001 & 88 & 336 & 0.747442 \\
2000 & 127 & 384 & 0.540306 \\
1998 & 293 & 784 & 0.167688 \\
1997 & 261 & 810 & 0.294909 \\
1996 & 197 & 514 & 0.262795 \\
\hline
\end{tabular}

\subsection{The length of articles in relation to the number of references}

The analysis of the relationship between the number of references and the number of pages per article is presented in Table 5. To obtain Pearson's correlation value, each article's total number of pages and references in each year were entered into two separate columns in Microsoft's Excel software, following which the Pearson's function, already explained under methodology, was applied to the data. Each year's articles and references produced the correlation values shown in column 4 in Table 5. The highest $r$ value was recorded in 2004 (i.e. $r=0.82$ ), followed by 200I (0.75), 2005 (0.63), 2000 (0.54) and 2006 (0.53). The rest of the years produced a Pearson's correlation value of less than 0.5 each. Overall, the Pearson product moment correlation coefficient stood at 0.407898 . 
Table 6 Language of consulted sources by SAJLIS authors

\begin{tabular}{ccccc}
\hline & English & Afrikaans & Others & Total \\
\hline 2007 & 506 & 5 & 3 & 514 \\
2006 & 809 & & 1 & 810 \\
2005 & 770 & 14 & & 784 \\
2004 & 380 & 4 & & 384 \\
2003 & 335 & & 1 & 336 \\
2002 & 234 & & & 234 \\
2001 & 178 & 4 & 1 & 183 \\
2000 & 98 & 5 & & 103 \\
1998 & 371 & 4 & & 375 \\
1997 & 609 & 17 & & 626 \\
1996 & 438 & 19 & 1 & 458 \\
Total & 4728 & 72 & 7 & 4807 \\
\hline
\end{tabular}

\subsection{Average number of pages per article}

The average number of pages per article was as follows: 1996 (II.6), 1997 (II.9), 1998 (II.7), 2000 (10.6), 200I (8.8), 2002 (10.9), 2003 (9.1), 2004 (9.8), 2005 (8.2), 2006 (8.5), and 2007 (8.I). Illustrating this distribution pattern in a line graph shows a general decrease in the length of articles (see Fig 3).

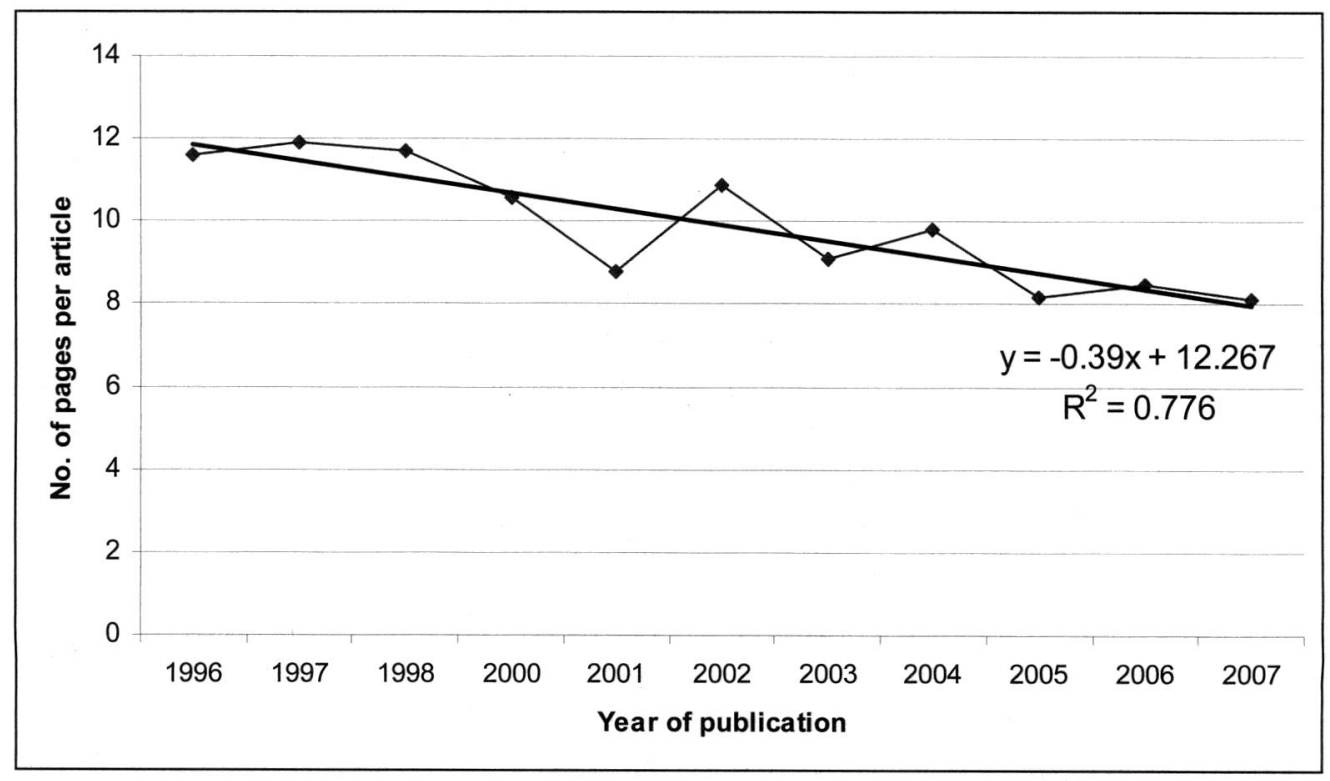

Fig 3: Number of pages per article

\subsection{Distribution of references by language}

The language of most of the consulted published literature by SAJLIS was obtained by examining the language in which the cited reference's title was written. It was observed that most of the cited sources in SAJLIS were in English, which yielded a total of 4728 references. In this category, the year 2006 produced the highest number (i.e. 809), followed by 2005 (770), 1997 (609) and 2007 (506). Sources in the Afrikaans language were also noted. They equated to 72 in total, with 1996 yielding the highest number (i.e. 19). With the exception of 2005 , when a total of 14 references were recorded in the Afrikaans language, it appears as though since 1998, Afrikaans language sources are seldom consulted by SAJLIS authors. 'Others' comprised the Dutch and French languages. 
Table 7 Types of sources consulted

\begin{tabular}{cccccccc}
\hline Year & $\begin{array}{c}\text { Journal } \\
\text { articles }\end{array}$ & $\begin{array}{c}\text { Electronic } \\
\text { journals }\end{array}$ & $\begin{array}{c}\text { Internet } \\
\text { sources }\end{array}$ & Books & $\begin{array}{c}\text { Conference } \\
\text { papers }\end{array}$ & Others & Total \\
2007 & 230 & 7 & 111 & 120 & 26 & 20 & 514 \\
2006 & 445 & 6 & 152 & 136 & 43 & 28 & 810 \\
2005 & 314 & 14 & 157 & 251 & 27 & 21 & 784 \\
2004 & 202 & 13 & 38 & 89 & 32 & 10 & 384 \\
2003 & 167 & 6 & 56 & 74 & 8 & 25 & 336 \\
2002 & 63 & 6 & 57 & 91 & 7 & 10 & 234 \\
2001 & 72 & 2 & 4 & 91 & 13 & 1 & 183 \\
2000 & 44 & 0 & 1 & 56 & 1 & 1 & 103 \\
1998 & 128 & 0 & 74 & 159 & 8 & 6 & 375 \\
1997 & 364 & 0 & 14 & 225 & 12 & 11 & 626 \\
1996 & 212 & & 1 & 220 & 12 & 13 & 458 \\
Total & 2241 & 54 & 665 & 1512 & 189 & 146 & 4807 \\
\hline
\end{tabular}

\subsection{Types of sources mostly consulted by SAJLIS authors}

It is evident from Table 7 that researchers who publish in SAJLIS largely make use of journal articles when publishing their research articles. Table 7 indicates that journal articles were the most commonly consulted document type. This document type produced 224I (46.6I\%) references, followed by books (I5I2 or 3I.45\%), internet sources (665 or $13.83 \%$ ), and electronic journals (189 or $3.93 \%$ ). There was a sixth category that we named 'others' (personal interviews; emails; reports; letters, etc) that recorded a total of 146 (3.03\%) references. There were also 54 (I.12\%) referrals to conference proceedings. The number of internet-based sources was also found to have tremendously increased, from just I in 1996 to I57 in 2005, and thereafter decreasing to I52 in 2006 and III in 2007.

\section{Discussion}

Table 8 provides a statistical summary of SAJLIS' publications and reference patterns from 1996 to 2007. Generally, the publication of SAJLIS has been regular over the years under review, with the exception of 1999 when no issue was published. It was not immediately clear why the journal was not published in 1999. However, a telephone call to the outgoing Editor-in-Chief intimated that the situation could have been caused by changes in the management team and ownership of the journal. It was noted that some years yielded more documents than others; a situation that can be attributed to more issues of the journal being produced in a given year (e.g. special issues). According to the outgoing Editor-in-Chief, the journal is officially expected to publish only two issues per year. An additional (third) issue was introduced to reduce the backlog of articles, and also to check whether the publication of a third issue was feasible. It is widely known that irregular patterns of publication - wherein a journal publishes more issues or does not publish on time in a given year - are characteristic of journal production in Sub-Saharan Africa (see Adebowale, 200I). To a large extent, this can be attributed to funding issues: whenever there is a shortage of funds, journals are more likely to publish fewer issues in a year.

The findings reveal that whereas there has been a continued increase in the number of references per year since 2000 , there was generally a mixed pattern of growth, whereby some years recorded positive increases while others experienced negative growth. It is, of course, possible that fewer issues or articles were published in some of the latter's years. To better understand this pattern, we computed the average number of references per year, which showed that there were at least 20.60 references per article per year. This is a relatively high number of references. Source consultation by SAJLIS authors can therefore be said to be relatively impressive, going by an aggregated average of 29.3 references per article. However, it was observed that the range between the article with the most number of references and the article with the least number of references was quite high (i.e. 97) - the article with the highest number of references had I0I, while the one with the least had only 4 references. Whether the number of references per article can be used to gauge the quality of an article is a matter of debate. In their paper entitled "What do third world researchers lack? Documenting the peer review data", Jacobs \& Pichappan (2008) found that references played a significant role in the acceptance (or rejection) of manuscripts. The authors observed that the mean number of references in the rejected journal papers (i.e. 16.55) was approximately one-half (1/2) of those in the accepted journal papers (i.e. 32.46). Rejected conference papers recorded even fewer references (mean $=8.3$ ). Does this mean that the less the number of references the higher the chances that the manuscript will be rejected? And if so, is there a standard minimum number of acceptable references in a manuscript? 
Another objective of this study was to determine the use of various document types by SAJLIS researchers. As in several similar studies (e.g. Krampen, Becker, Wahner \& Montada, 2007; Vallmitjana \& Sabate, 2008), we noted a high use of journal articles by SAJLIS researchers. The preference for journal articles compared to other document types could be because journal articles are peer-reviewed, which makes them more reliable. Unlike books, they also provide current information. The use of internet-based sources and electronic journals is also on the rise. In the period under review, electronic journals first became visible in $200 \mathrm{I}$ with 2 citations, and this number grew to 14 in 2005. This may have affected the use of books, as shown in Table 2. Books were mostly consulted between 1996 and 2002, following which they were no longer the preferred source of information for most researchers. The information age has resulted in speedy access to current information, which is largely available electronically through e-databases, e-journals, and other e-resources that publish/index research findings. This may have caused the lesser frequency with which books are used. Furthermore, books do not always publish research findings which are commonly used by researchers to either conduct further research or support their own research.

Table 8 Descriptive statistical summary of references in SAJLIS

\begin{tabular}{|c|c|c|c|c|c|c|c|c|c|c|c|}
\hline & 1996 & 1997 & 1998 & 2000 & 2001 & 2002 & 2003 & 2004 & 2005 & 2006 & 2007 \\
\hline Mean & 25.44 & 27.22 & 23.44 & 20.60 & 26.14 & 23.40 & 33.60 & 32.00 & 31.36 & 36.82 & 30.24 \\
\hline Median & 23.5 & 22 & 22.5 & 20 & 20 & 21 & 21.5 & 31 & 28 & 33.5 & 29 \\
\hline Mode & 11 & 22 & 16 & 20 & 20 & 14 & - & 29 & 25 & 38 & 28 \\
\hline Std deviation & $|4.6|$ & 13.42 & 10.12 & 6.39 & $12.0 \mid$ & 10.46 & 32.23 & 10.84 & 14.74 & 20.83 & 10.12 \\
\hline Sample Variance & 213.44 & 180.09 & 102.40 & 40.80 & 144.14 & 109.38 & $1038.7 \mid$ & 117.45 & 217.32 & 433.77 & 102.44 \\
\hline Skewness & 1.37 & 0.80 & 0.13 & 0.31 & 1.52 & 0.42 & 1.51 & 0.32 & 0.75 & 0.92 & 0.26 \\
\hline Range & 57 & 44 & 32 & 18 & 36 & 27 & 97 & 33 & 49 & 76 & 50 \\
\hline Minimum & 10 & 12 & 7 & 12 & 14 & 11 & 4 & 18 & 13 & 10 & 6 \\
\hline Maximum & 67 & 56 & 39 & 30 & 50 & 38 & 101 & 51 & 62 & 86 & 56 \\
\hline Sum & 458 & 626 & 375 & 103 & 183 & 234 & 336 & 384 & 784 & 810 & 514 \\
\hline Count & 18 & 23 & 16 & 5 & 7 & 10 & 10 & 12 & 25 & 22 & 17 \\
\hline \multicolumn{12}{|l|}{ Confidence } \\
\hline Level (95.0\%) & 7.27 & 5.80 & 5.39 & 7.93 & 11.10 & 7.48 & 23.06 & 6.89 & 6.09 & 9.23 & 5.20 \\
\hline
\end{tabular}

There is no clear evidence of any relationship between the length of an article and the number of pages per article, despite the positive correlation between the two variables. The overall Pearson correlation coefficient of $0.4 \mathrm{I}$ is low, which means that the relationship between the length of articles and the number of references is too weak. It therefore follows that the length of an article does not influence the number of references, and vice versa.

An examination of the length of articles revealed that the average number of pages per article has continued to decrease over time from II.9 in 1997 to 8.1 in 2007. In terms of word count, the size of an average article in SAJLIS has therefore reduced from about 5950 to 4050 words, when calculated at approximately 500 words per page set at a font size of 12 and Times New Roman font type. This is a worrying trend as journals have standards to maintain. In its policy, SAJLIS stipulates that acceptable manuscripts should be 5000 to 7000 words in length. Despite this condition, articles with as few pages as 5 (or 2500 words) were published in the journal. In fact, out of the 165 articles that SAJLIS published between 1996 and 2007, 58 were 8 or less pages long. The distribution pattern of the number of articles according to the number of pages were as follows: 5 pages (8); 6 pages (8); 7 pages (23); and 8 pages (19). This trend, if unchecked, is likely to compromise the quality of the journal.

In terms of the document types that are published in SAJLIS, it was observed that most were journal articles, followed by book reviews and editorials. Editorials, which in most cases provide a summary of the contents published in an issue, came into being in $\mathbf{2 0 0 2}$ when new members of the journal's management team (including the Editor-in-Chief) were appointed.

The language of publication of the consulted sources was another variable that was analysed in this study. It was found that most of the consulted sources by SAJLIS authors were written in the English language. Although they are minimal, sources in the Afrikaans language were also visible. A trend analysis of the references indicates that the consultation of sources published in the Afrikaans language by SAJLIS authors is dwindling. This is perhaps because English is increasingly becoming the main language of scholarly communication, not only in South Africa, but also in the rest of the world. In fact,

SA Jnl Libs \& Info Sci 2008, 74(2) 
in its policy, SAJLIS stipulates that all manuscripts should be submitted in the English language - a departure from its previous policy, where it allowed the submission of manuscripts in the Afrikaans language. In our view, the current policy is likely to ensure that SAJLIS remains internationally visible, which would increase its chances of being cited. Perhaps this explains why SAJLIS has improved in terms of its citation rate and impact factor (see Onyancha, 2008).

Going by Neville's (2007) assertion that references are provided to assist readers who wish to follow up the sources that the researcher cited, or to support their own arguments and develop further ideas for research; it follows that the more cited references in an article the better. We believe that a longer list of cited references provides a gateway to a larger amount of information related to the content in the citing article than a shorter one. With respect to this, we identified the articles with the highest number of references. In the analysis, it became immediately evident that some of the top-citing articles originated from the authors' Masters or Doctoral dissertations and theses. Possibly, the authors had a longer time to conduct a literature review during their studies, hence the high number of references. Further research, however, is recommended to find out whether or not this hypothesis is valid.

\section{Conclusion and recommendations}

In conclusion, SAJLIS, being the oldest and core journal through which LIS research in South Africa and the rest of SubSaharan Africa is disseminated (see Onyancha, 2008), needs to maintain regular publication so that it remains visible and viable, both nationally and internationally. The journal's delayed production could negatively affect its visibility and impact, hence the need, on the part of the sponsor to ensure that it is produced regularly and on time. The management team should consider nominating the journal for indexing in Thomson Scientific's citation databases and in Scopus in order to increase visibility and demonstrate quality. Currently, there is only one LIS journal from Sub-Saharan Africa included in Thomson Scientific's citation indexes, i.e. African Journal of Archives, Library and Information Science. These citation indexes are the most commonly used tools to evaluate research, researchers (individuals, institutions and even countries) and journals. Regular publication of the journal should therefore be maintained not only for purposes of visibility and impact but also continued subsidy from South Africa's Department of Education. The journal's owners and its management team should also consider publishing the journal online, i.e. the journal should have its own website. In addition to the information that is already posted on the LIASA website about the journal, the management team is advised to provide the abstracts and references of each article on the website. This would ensure that if an individual browses the Internet and comes across a reference (that is of interest) contained in SAJLIS, he/she may request the article that contains the cited reference. In this way, we believe that SAJLIS can broaden its circulation and thereby increase its visibility and impact in the scholarly community.

\section{References}

Adebowale, S.A. 200I. The scholarly journal in the production and dissemination of knowledge on Africa: exploring some issues for the future. African Sociological Review, 5(I): I-I5.

Aronsky, D., Madani, S., Carnevale, R., Duda, S. \& Feyder, M. 2007. The prevalence and inaccessibility of Internet references in the biomedical literature at the time of publication. Journal of the American Medical Informatics Association, 14(2): 232-234.

Biglu, M. 2008. The influence of references per paper in the SCl to impact factors and the Matthew effect. Scientometrics, 74(3): 453-470.

Crawly-Low, J. 2006. Bibliometric analysis of the American Journal of Veterinary Research to produce a list of core veterinary medicine journals. Journal of the Medical Library Association, 94(4): 430-434.

Diodato, V. 1994. Dictionary of bibliometrics. New York: The Haworth Press.

Glanzel, W \& Schoepflin, U. 1999. A bibliometric study of reference literature in the sciences and social sciences. Information Processing and Management, 35(I999): 3I-44.

Jacobs, D. 2006. Analysis of Scientific Research in selected institutions in South Africa: A bibliometric study. South African journal of Libraries and Information Science, 72(I): 72-77.

Jacobs, D. \& Pichappan, P. 2008. What do third world researchers lack? Documenting the peer review data. Paper presented at the $10^{\text {th }}$ LIASA Annual conference, 6-10 October 2008, Cape Town, South Africa. Available: http://www.liasa.org.za/ conferences/conference2008/presentations.php Accessed 23 October 2008.

Kirchler, E \& Holzl, E. 2006. Twenty-five years of the journal of Economic Psychology (198|-2005): A report on the development of an interdisciplinary field of research. Journal of Economic Psychology, 27(2006): 793-804.

Koehler, W and others. 2000. A bibliometric analysis of selected information science print and electronic journals in the 1990s. [Online]. Information Research, 6(I). http://informationr.net/ir/6-//paper88.html Accessed 13 October 2008.

Krampen, G., Becker, R., Wahner, U. \& Montada, L. 2007. On the validity of citation counting in science evaluation: content analyses of references and citations in psychological publications. Scientometrics, 7I(2): 191-202.

Mabawonku, I. 200I. Trends in library and information science research in Africa, 1991-2000. African Journal of Library, Archival and Information Science, II (2): 79-88.

Neville, C. 2007. The complete guide to referencing and avoiding plagiarism. McGraw Hill: Open University Press.

SA Jnl Libs \& Info Sci 2008, 74(2) 
Ocholla, D.N. 2005. Insight into the Management of LIS Journals: Some Africa Perspectives. In L.O. Aina \& A.A. Alemna and lyabo Mabawonku(Eds), Improving the quality of Library and Information Science Journals in West Africa: A stakeholders Conference. Proceedings of the Stakeholders Conference, held at the University of Ibadan, Nigeria, 7-8 December 2005: pp I-18.

Ocholla, D.N. 2007. Common errors and challenges in publishing in a peer refereed library and information journal. South African Journal of Libraries and Information Science, 73(I): I- I3.

Ocholla, D N \& Ocholla, L. 2007. Research in Library and Information Science in South Africa: an analysis of journal research output from 1993-2006. South African Journal of Libraries and Information Science, 73(2): 109-II8.

Ojedokun, A.A. 2007. Information literacy for tertiary education students in Africa. Ibadan, Nigeria: Third World Information Services.

Omotayo, B O. 2004. A Content analysis of IFE Psychologia, 1993 - 2002. The International Information \& Library Review, 36:95103.

Onyancha, O.B. 2006. Empowering the South African community's AIDS intervention workforce: an informetric analysis study of HIV/AIDS research projects, with special reference to masters and doctoral dissertations and theses. South African Journal of Libraries and Information Science, 72(I): 56-7I.

Onyancha, O.B. 2008. "It is now feasible": a citation analysis of Sub-Saharan African LIS journals. A paper presented at the Annual Faculty of Arts conference, University of Zululand, 16 September 2008. Available: http://www.arts.uzulu.ac.za Accessed 03 November 2008.

Ovens-Cora S H. 1995. Citation patterns of University of the Orange Free State scientists. South African journal of libraries and information Science, 62(2): 47-55.

Robinson, A.M \& Schlegl K. 2004. Students bibliographies Improve when Professors Provide Enforceable Guidelines for Citation. Libraries and the Academy, 4(2): 275-290.

Smith, L. C. (198I). Citation analysis. Library Trends, 30: 83-106.

Thomas, A \& Goldman, G. 2007. Referencing in academic documents: guidelines. Available: University of Johannesburg website. http://www.uj.ac.za/LinkClick.aspx?fileticket=FtmPiw9GC7E\%3D\&tabid=6994 Accessed 15 May 2008.

Tiew, W. S., Abdullah, A \& Kaur, K. 2002. Malaysian Journal of Library and Information Science 1996 - 2000: a bibliometric study. Malaysian Journal of Library \& Information Science, 6(2): 43-56.

Ungern-Sternberg, S. (2000). Scientific communication and bibliometrics. Available: http://abo.fi/ sungern/comm00.htm Accessed 19 March 2002.

Vallmitjana, N. \& Sabate, L.G. 2008. Citation analysis of Ph.D. dissertation references as a tool for collection management in an academic chemistry library. College \& Research Libraries, 69(I): 72-8I.

\section{Appendix A}

\section{Top twenty articles with the most references}

\begin{tabular}{|c|c|c|c|c|}
\hline Rank & Author(s) & 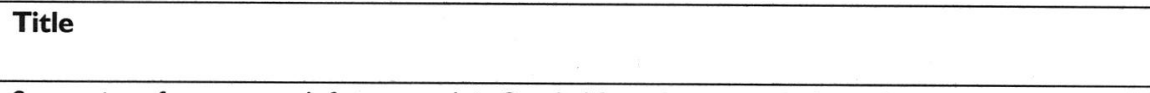 & $\begin{array}{l}\text { No of } \\
\text { References }\end{array}$ & Year \\
\hline I & Fourie, I. & $\begin{array}{l}\text { Suggestions for a research frame work in South Africa: how can we learn from web information } \\
\text { seeking /searching studies? }\end{array}$ & 101 & 2003 \\
\hline 2 & $\begin{array}{l}\text { Ikoja-Odongo, R. } \\
\text { \& Mostert, J }\end{array}$ & Information seeking behaviour: A conceptual framework & 87 & 2006 \\
\hline 3 & $\begin{array}{l}\text { Stilwell, C \& } \\
\text { Morris, C. }\end{array}$ & $\begin{array}{l}\text { Getting the write message right: Review of guidelines for producing readable print agricultural } \\
\text { information materials }\end{array}$ & 82 & 2003 \\
\hline 4 & Migiro, S O. & Diffusion of ICTs and E-commerce adoption in manufacturing SMEs in Kenya & 73 & 2006 \\
\hline 5 & $\begin{array}{l}\text { Ngulube, P \& } \\
\text { Magazi, L }\end{array}$ & $\begin{array}{l}\text { Protecting documents against disasters and theft: the challenge before the public libraries in } \\
\text { KwaZulu-Natal, South Africa }\end{array}$ & 73 & 2006 \\
\hline 6 & Fourie, J A. & $\begin{array}{l}\text { Co-Operation between schools and public libraries: meeting pupils' needs for information in } \\
\text { independent learning }\end{array}$ & 71 & 1996 \\
\hline 7 & Dick, A L & $\begin{array}{l}\text { 'Send your books on active service': The books for troops scheme during the Second World War, } \\
\text { 1939-1945 }\end{array}$ & 62 & 2005 \\
\hline 8 & $\begin{array}{l}\text { Dube, L \& } \\
\text { Ocholla, D N }\end{array}$ & $\begin{array}{l}\text { Insight into the management and diffusion strategies of HIV/AIDS Information in institutions of } \\
\text { Higher Education in South Africa }\end{array}$ & 61 & 2005 \\
\hline 9 & Murray, K. & Preservation education in South African library and archive degree programmes & 60 & 2006 \\
\hline 10 & Weideman, $M$. & FOIOTI: An implementation of the conceptualist approach to Internet Information Retrieval & 57 & 2005 \\
\hline 11 & Fairer-Wessels, F & Information management education: Towards a holistic perspective. & 56 & 1997 \\
\hline 12 & Hart, G & Social capital: a fresh vision for public libraries in South Africa? & 56 & 2007 \\
\hline 13 & Stilwell, C & First professional, in-service and continuing education and training provincial library staff... & 52 & 1997 \\
\hline 14 & $\begin{array}{l}\text { Kwake, A, } \\
\text { Ocholla, D.N. \& }\end{array}$ & The feasibility of ICT diffusion and use amongst rural women in South Africa & 51 & 2006 \\
\hline
\end{tabular}


15 Onyancha, O B \& An informetric analysis of the corruption literature based on Africa between 1990 and 200 I Ocholla,D N

16 Leach, $\mathrm{A}$

Information provision in a rural context: the perspectives of rural adults.

$50 \quad 2001$

17 Hart, G

Public libraries in South Africa - agents or victims of educational change?

18 Machet, M.P. \&

Literacy environment of pupils in urban primary schools.

Olen, S.I.I. 